\title{
A VULNERABILIDADE DO CONSUMIDOR E A EXPOSIÇÃO PÚBLICA NA INTERNET
}

Cinthia Obladen de Almendra Freitas

Doutora em Informática pela Pontifícia Universidade Católica do Paraná (PUCPR). Professora Titular da Pontifícia Universidade Católica do Paraná (PUCPR) para os cursos de Direito (Módulos Temáticos: Perícias e Laudos Técnicos e Crimes e Fraudes por Computador) e Ciência da Computação. Professora Permanente do Programa de Pós-Graduação em Direito (PPGD) da PUCPR. Pesquisadora do Grupo de Pesquisa "Direito do Consumo e Sociedade Tecnológica" (PUCPR/ CNPq).email: cinthia@ppgia.pucpr.br

\section{Resumo}

O artigo trata o usuário da Internet e das redes sociais que diante do Código de Defesa do Consumidor equipara-se ao consumidor e, portanto, questiona a exposiçáo pública deste usuário que faz crescer a vulnerabilidade do consumidor. O indivíduo é o mesmo, mas a atuação é distinta e complexa, visto que quanto maior a exposição maior é a vulnerabilidade e, portanto, como esperar que este usuário-consumidor se porte de maneira consciente diante do que revela de si próprio? $\mathrm{O}$ artigo apresenta ainda uma visáo da realidade brasileira e espanhola no que concerne à sociedade de exposiçáo. Finalmente, são analisados os mecanismos de recomendação utilizados, pelos sites e redes sociais, para influenciar o poder de decisão do consumidor. Conclui-se que o excesso de informação mostra-se atrelado ao excesso de exposição e este elo torna-se forte à medida que a vulnerabilidade do consumidor é aumentada.

\section{Palavras-chave}

Sociedades; Consumidor; Exposição; Vulnerabilidade; Novas Tecnologias; Mecanismos de Recomendação.

\section{Resumen}

El artículo trata del usuario de Internet y de las redes sociales que ante el Código de Defensa del Consumidor se equipara al consumidor y, por lo tanto, cuestiona la exposición pública de este usuario que hizo crecer la vulnerabilidad del consumidor. El individuo es él mismo, sin embargo la actuación es distinta y compleja, ya que cuanto mayor sea la exposición, mayor es la vulnerabilidad y, por consiguiente, cómo esperar que este 
usuario-consumidor se porte de manera consiente ante lo que revela de sí mismo. El artículo presenta todavía una visión de la realidad brasileña y española en lo que concierne a la sociedad de exposición. Finalmente son analizados los mecanismos de recomendación utilizados por los sitios web y las redes sociales para influenciar el poder de decisión del consumidor. Se concluye, que el exceso de información se junta al exceso de exposición, y este enlace se fortalece a medida en que la vulnerabilidad del consumidor aumenta.

\section{Palabras clave}

Sociedades; Consumidor; Exposición; Vulnerabilidad; Nuevas Tecnologías; Sistemas de Recomendación.

\section{Introdução}

A Internet é meio para toda modalidade de ação das pessoas. Na Internet é possível buscar, comprar, consultar, compartilhar, marcar, postar, navegar, pagar e, até mesmo, se relacionar. Algumas açóes têm se tornado cada dia mais presente, tais como: postar, compartilhar e se relacionar. As açôes migraram do mundo físico e analógico (cartas, panfletos, fotografias) para o mundo digital (e-mail, sites, imagens). As Tecnologias de Informação e Comunicação (TIC) nunca foram tão presentes na vida das pessoas quanto nos últimos 10 anos e, portanto, despertam interesse tanto por parte dos usuários quanto dos pesquisadores.

Desde as primeiras transmissóes de dados entre computadores até a criação da ARPANET (abril de 1969) e da Internet (na década de 70 e 80 com fins acadêmicos e a partir da década de 90 com o desenvolvimento do serviço World Wide Web, a Internet pode ampliar seus horizontes e quantidade de seus usuários) e mais recentemente por meio das redes sociais, foram deflagradas mudanças comportamentais, sociais e econômicas nunca antes verificadas.

O surgimento da sociedade de informação na década de 60, agregado ao desenvolvimento das Tecnologias de Informação e Comunicação (TIC), permitiu a quebra de paradigmas, dentre estes os relacionados à informação, tornado-a objeto de maneira a possibilitar que a sociedade se organize em torno da informação.

Neste contexto, a informação é o elemento mais importante e vital para a existência e também sobrevivência das redes sociais. RECUERO (2005, p. 5) afirma que

... a análise estrutural das redes sociais procura focar na interação como primado fundamental do estabelecimento das relaçóes sociais entre os agentes humanos, que originarão as redes sociais, tanto no mundo concreto, quanto no mundo virtual. 
FREITAS (2012, p. 44) reforça tal entendimento quando analisa o surgimento das redes a partir da Teoria dos Grafos de maneira a estabelecer os vértices como sendo as pessoas (instituições ou grupos) e as arestas como sendo as conexôes estabelecidas pelos vértices. Nesta trama, rede ou grafo, os indivíduos não estão isolados e possuem certo grau de dependência da relaçáo ou conexão com os outros indivíduos ou grupos.

Veicula-se todo tipo de dado, ou seja, texto, imagem, vídeo, áudio; com velocidade, acessibilidade e mobilidade nunca antes possível. Além disto, as redes sociais possuem efeito multiplicador à medida que os amigos dos amigos podem ter acesso ao que é postado. Portanto, estabelece-se um ciclo no qual a informação gera mais informação e é veiculada por mais e mais pessoas, nos lugares mais distantes. $\mathrm{O}$ interesse por acessar informaçóes é crescente e para tal gera-se uma estrada de mão dupla, ou seja, para receber é necessário dar. Além disto, divulgar, compartilhar e postar informaçôes envolve tanto dados pessoais e não pessoais quanto dados sensíveis.

O excesso de informação mostra-se atrelado ao excesso de exposição, exposição esta sem limites de cada indivíduo de maneira a refletir seus gostos, modo de vida, interesses, amigos, pensamentos e atitudes. As conhecidas "selfies" (imagens de si próprio) são veiculadas constantemente nas redes sociais. Não se discutem no artigo os aspectos de fugacidade ou de banalidade, mas busca-se entender a sociedade de exposiçáo. E, portanto, a sociedade da informação sustenta a sociedade da exposição? Ou é o oposto?

$\mathrm{O}$ artigo trata sobre o usuário da Internet e das redes sociais que diante do Código de Defesa do Consumidor equipara-se ao consumidor e, portanto, questiona a exposição pública deste usuário que faz crescer a vulnerabilidade do consumidor. $\mathrm{O}$ indivíduo é o mesmo, mas a atuação é distinta e complexa, visto que quanto maior a exposição maior é a vulnerabilidade e, para tanto, pergunta-se: Como esperar que este usuário-consumidor se porte de maneira consciente diante do que revela de si próprio?

$\mathrm{O}$ artigo segue método dedutivo de pesquisa para relacionar a sociedade de exposição e a vulnerabilidade dos consumidores aos mecanismos de recomendação utilizados nas redes sociais e demais aplicativos voltados ao consumidor, discutindo os limites frente ao Código de Defesa do Consumidor.

Questiona-se: Como a sociedade de exposição consome? Que mecanismos são utilizados para influenciar o consumo nesta sociedade? Existe relação entre o comportamento do usuário de Internet e, também, consumidor no Brasil e na Espanha? A Legislação brasileira é eficaz ao tutelar o consumidor? Quão vulnerável está o consumidor diante de mecanismos que podem influenciar o seu poder de decisão? Muitos são os questionamentos e, portanto, tais aspectos são merecedores de atenção e estudo. 


\section{A Exposição Pública na Internet}

BELLO (2012, p. 1) mostra que a partir de pesquisa da empresa F-Secure que " $86 \%$ dos brasileiros dizem se expor demais nas redes sociais". RUIZ e RÍO (2009, p.97) mostram que " $88,1 \%$ dos jovens na Espanha publicam dados pessoais reais em seus perfis nas redes sociais".

A exposição é real e faz com que conceitos, tais como: visibilidade, identidade e privacidade; se tornem relevantes. Por outro lado, existem as técnicas computacionais que permitem desde a indexação da informação até a mineração de textos, a qual é entendida como o processo de obtenção de informação de qualidade a partir de textos em linguagem natural (FELDMAN e SANGER, 2007, p. 1). Podem ser incluídas ainda as técnicas de agrupamento ou clusterização (TAN et al., 2009, p. 1).

Estas técnicas possibilitam desde associaçóes simples (por exemplo: qual é o conjunto de consumidores que acessa um determinado site e reside numa determinada cidade?) até associaçóes complexas, por exemplo: qual a emoção associada a um post de um determinado usuário em uma rede social?

Parte-se do objeto redes sociais como infraestrutura meio ao acesso, compartilhamento, postagem e veiculação de dados e informações (pessoais ou não, sensíveis ou não). Para tal, tem-se que as redes sociais são um meio de comunicação que aproximam e facilitam o contato entre as pessoas, como afirma MARTELETO (2001, p. 72):

As Redes Sociais representam um conjunto de participantes autônomos, unindo ideias e recursos em torno de valores e interesses compartilhados. A questão central das redes é a valorização dos elos informais e das relações, em detrimento das estruturas hierárquicas. As redes sociais são exatamente as relações entre os indivíduos na comunicação mediada por computador. Esses sistemas funcionam através da interação social, buscando conectar pessoas e proporcionar sua comunicação.

No entanto é importante observar que as redes sociais não somente apresentam vantagens, mas riscos. A exposição exacerbada necessita que cada vez mais se conheça o limite do privado e pessoal diante do que se torna público. TRUZZI (2015, p. 3) mostra que

Vemos que há perigos bem reais do uso inconsciente deste tipo de aplicativo das redes sociais: riscos de ser furtado, excesso de exposição, reflexos negativos na vida corporativa e complicaçóes na vida pessoal.

Os riscos são complexos e incluem desde os crimes de calúnia, difamação e injúria, passando pelo cyberbullying, furto, estelionato e invasão de dispositivo informático de outrem. Pode-se somar a esta lista o problema relacionado com a adição à Internet, ou seja, o vício por Internet e jogos digitais (ECHEBURÚA e CORRAL, 2010, p. 91). Este artigo 
não esgota o tema e, por conseguinte, não aborda tais problemas, mas registra que devem ser discutidos mecanismos de prevenção, bem como, políticas públicas.

Cabe, portanto, conceituar a sociedade de exposição e entender suas premissas para que o usuário das redes sociais, ora consumidor, possa ser contextualizado e, então, avaliar a vulnerabilidade daquele que "navega" e consume na Internet.

\subsection{Sociedade de Exposição: Conceito e Premissas}

A exposição surge do momento em que para utilizar software ou aplicativos de redes sociais, os usuários necessitam, inicialmente, cadastra-se e, logo, criar o que é conhecido como perfil. Para RECUERO (2009, p. 121) tais softwares fazem parte do grupo de programas computacionais ditos sociais, assim entendidos como sendo "softwares com aplicação direta para a comunicação mediada por computador".

Além disto, ao se comunicar por meio das redes sociais, as conexóes entre usuários são exponenciais devido à característica técnica de que a partir de um usuário derivam-se novas conexóes, ou seja, a partir dos "amigos" ou usuários que integram a rede individual de cada usuário. Assim, amigos dos amigos que também possuem amigos, fazem com que tudo que é postado, escrito ou falado seja rapidamente espalhado pela rede mundial de computadores.

RECUERO (2009, p. 121) aponta que a estrutura da rede social é o elemento "cuja principal característica é a exposição pública da rede dos atores, que permite mais facilmente divisar a diferença entre esse tipo de site e outras formas de comunicação mediada pelo computador".

Na língua portuguesa, no Brasil, exposição é "substantivo feminino. Exibição pública; revelação" (BUENO, 2007, p. 341). Nota-se que a exibição vem acompanhada do termo pública, ou seja, aos outros, à sociedade ou àqueles que integram uma rede de relacionamentos, sejam estes relacionamentos reais ou virtuais.

Neste contexto, entende-se a formação da cultura de exposição tal qual descrita por Tim Wu, professor da Columbia University, explicando que "A cultura da exposição reflete a filosofia da web, na qual ser percebido é tudo". ANDERSON (2006, p. 72) em seu livro "A Cauda Longa" (The Long Tail), mostra o que Tim Wu entende por cultura da exposição, a saber:

A cultura da exposiçáo reflete a filosofia da Web, na qual ser percebido é tudo. Os autores da Web se ligam uns aos outros, citam com liberalidade e, às vezes, comentam ou anotam artigos inteiros. A transmissão por e-mail de links para artigos ou piadas favoritas integrou-se na cultura dos ambientes de trabalho americana, tanto quanto as conversas 
de bebedouro. O grande pecado da cultura da exposição não é copiar, mas, em vez disso, deixar de citar de maneira adequada a autoria. No centro dessa cultura da exposição situa-se o todo poderoso software de pesquisa. Se for fácil encontrar o seu site no Google - não o acione em juízo, comemore.

O autor contextualiza a exposição no Direito de Autor, mas a preocupação é cabível a este artigo assim como é o conceito de exposição. A sabedoria popular dita que "quem não está ou não pode ser encontrado por meio da Internet, não existe”. Então, a informação gerou uma sociedade e a exposição também está gerando uma sociedade. Entenda-se, sociedade de exposição pelo conjunto de pessoas que se utilizam das redes sociais para manter e ampliar os modos de comunicar e relacionar.

Isso mostra que o conteúdo pode ser compartilhado de forma livre, sendo o conteúdo inclusive sobre o próprio indivíduo que o produz e posta nas redes sociais. Este conteúdo autobiográfico tornou-se comum e vem sendo potencializado pelas redes sociais. SIBILIA (2003, p. 5) explica que "Todas essas tendências de exposição da intimidade que proliferam hoje em dia, portanto, vão ao encontro e prometem satisfazer uma vontade geral do público: a avidez de bisbilhotar e "consumir" vidas alheias".

Fica implícito nestes entendimentos que os indivíduos que formam a sociedade de exposição compartilham interesses ou preocupaçóes mútuas a partir de um objeto ou objetivo comum. A sociedade de exposição tem seus atores como o objeto de interesse e como objetivo expor-se.

A estrutura da rede social associada à exposição confere aos seus usuários o caráter lúdico e divertido, mas também permite transmitir maior confiança e fidelidade ao usuário. É necessário sopesar também a característica de uma nova geração de usuários, os chamados "nativos digitais", assim denominados por PRENSKY (2001, p. 1). DAL BELLO (2011, p. 149) relata que

em 1 de outubro, por ocasião do lançamento do Google Street View no Brasil, perguntei a um jovem (aqui nomeado Jr., 19 anos) se ele não ficava "assustado" com tamanha exposição. Afinal, lá estava a sua rua, a sua casa, o seu portão. Ele respondeu que não, afinal, "minha geração cresceu com a Internet. A gente não está muito preocupada com essa tal privacidade. Pra gente, isso é normal". Ficou patente que o termo marcava um diferencial entre nós: seu descaso pela problemática estava em consonância com o orgulho por pertencer a uma nova geração.

A exposição pública nas redes sociais e na Internet merece estudos para possibilitar o entendimento dos paradigmas atuais, mas também para buscar formas de veiculação das informaçóes de modo seguro e adequado. Saber que exposição está atrelada a riscos, os mais variados possíveis, faz o "navegar" mais seguro e torna os usuários mais conscientes 
de suas açóes e, ainda, das repercussóes que suas ações podem causar, seja no mundo digital ou no mundo real.

\section{Consumindo na Sociedade de Exposição}

$\mathrm{O}$ consumir mudou. Na verdade, o que mudou foi o meio pela qual se concretiza a relação de consumo. As relaçóes face-to-face passaram a ser realizadas pela Internet, o chamado comércio eletrônico (e-commerce). Deste modo, com o advento da computaçáo móvel (celulares, smartphones e tablets), das redes sociais, da TV digital interativa (TVDi) e, ainda, das redes de alta velocidade pode-se desenvolver e implementar novas modalidades de comércio eletrônico focadas nos seguintes elementos básicos: $\mathrm{m}$ - mobilidade, $\mathrm{s}$ - social, $\mathrm{t}$ - televisão e $\mathrm{f}$ - Facebook. Surgiram então: $m$-commerce (mobile-commerce), s-commerce (social-commerce), t-commerce (TV-commerce) e f-commerce (Facebook-commer$c e$ ), ou seja, o denominado $m$-s-t-f-commerce.

As indicaçóes apontadas por amigos realizadas boca a boca, hoje se transformaram em mecanismos de recomendação que processam automaticamente as avaliaçóes de uma grande quantidade de usuários e consumidores. De acordo com JENKINS (2006, p. 222) tem-se que

Hoje, o consumo assume muito mais uma dimensão pública - não mais uma questão de escolhas e preferências pessoais, o consumo se tornou tema de discussóes públicas e deliberaçôes coletivas; o compartilhamento de interesses comumente leva a conhecimento compartilhado, visóes compartilhadas e ações compartilhadas.

Os consumidores ganham uma proporção distinta e realçada por meio das trocas de informações. Além disto, tais trocas aceleram a maneira com que usuários e recomendações são colocados em contato e, portanto, o poder de decisão do consumidor sofre influências, permitindo uma maior visibilidade aos interesses de consumo e, também, diretamente ao consumo. ANDERSON (2006, p. 55) corrobora apresentado que

A capacidade de explorar a inteligência dispersa de milhôes de consumidores para que as pessoas encontrem o que lhes é mais adequado está determinando o surgimento de todos os tipos de novas recomendaçóes e métodos de marketing atuando basicamente como os novos formadores de preferências.

A combinação entre pessoas, Internet, recomendaçôes e procedimentos automáticos de tratamento de informaçóes está permitindo que o paradigma denominado everyware, proposto por GREENFIELD (2006, p. 9), seja a cada dia uma realidade mais presente na vida de todos: 
Ever more pervasive, ever harder to perceive, computing has leapt off desktop and insinuated itself into everyday life. Such ubiquitous information technology - "everyware" - will appear in many different contexts and take a wide variety of forms, but it will affect almost every one of us, whether we're aware of it or not ${ }^{1}$.

Coube, portanto, ao artigo analisar o usuário e consumidor, tanto no Brasil quanto na Espanha para contextualizar a sociedade de exposição, bem como, entender os mecanismos de recomendação utilizados, pelos sites e redes sociais, para influenciar o poder de decisão do consumidor.

\subsection{Dados Estatísticos: Brasil e Espanha}

Cabe conhecer a realidade brasileira e espanhola no que concerne à sociedade de exposição de modo a contribuir com o entendimento do processo de globalização, o qual por natureza é complexo e envolve o estudo de um sistema multivariáveis. Tornam-se relevantes, portanto, dados estatísticos apresentados em trabalhos científicos e também por empresas que se interessam pelo setor, seja do ponto de vista cultural, comportamental ou econômico.

Os estudos sobre redes sociais trazem naturalmente à discussão o Facebook, rede social mais utilizada no Brasil de acordo com levantamento realizado pela ferramenta de inteligência em marketing digital da Serasa Experian, a Hitwise ${ }^{2},{ }^{3}$. Os dados referem-se ao último trimestre de 2013 e revelam que no Brasil a "maior audiência das redes sociais é composta por pessoas da faixa etária de 25 a 34 anos (27,45\%), seguido pela faixa de 18 a 24 anos (23,57\%), e pelas pessoas com idade entre 35 e 44 anos $(20,46 \%)$ ". Além disto, o Facebook ocupa o $1^{\circ}$. lugar entre as redes sociais com $67,96 \%$ dos usuários brasileiros. $\mathrm{O}$ estudo aponta que o Facebook em 2013 ultrapassou até o Google em número de acessos no Brasil. O sucesso refletiu em 1,5 bilhôes de usuários cadastrados na rede. Desses, 83 milhóes são usuários do Brasil, o terceiro maior país no Facebook. No topo, os Estados

1 Tradução livre: 'Ainda mais invasivo, mas difícil de perceber, é que o computador saiu da mesa de trabalho e se insinua em nossa vida diária. Essa tecnologia da informação ubíqua - 'everyware’ aparecerá em muitos contextos diferentes e tomará uma variedade de formas, mas afetará quase todos nós, estejamos ou não conscientes disto’.

2 Disponível em <http://top10mais.org/top-10-redes-sociais-mais-acessadas-do-brasil/> Acesso em 15 mai. 2015.

3 "A Hitwise da Serasa Experian é uma ferramenta global de inteligência digital, utilizada diariamente por centenas de clientes de diversos segmentos, entre agências de publicidade, veículos de comunicação e anunciantes. Por meio de parcerias com empresas de painéis sindicalizados (opt-in), a Hitwise provê métricas qualificadas sobre o comportamento anônimo e agregado de mais 1 milhão de pessoas no Brasil". Disponível em <https://marketing.serasaexperian.com.br/consumer-insights/hitwise/> Acesso em 15 mai. 2015. 
Unidos, possuem 179 milhóes de usuários, seguido pela Índia com 100 milhóes. Porém, quando se leva em conta o número de usuários ativos, o Brasil fica em segundo lugar, pois, 47 milhões de brasileiros acessam o Facebook todos os dias.

O site Facebook.com foi criado em 2004, tendo sido liberado para o grande público em 2006, nos Estados Unidos da América. No início, o Facebook era destinado a estudantes e a professores, de forma que o acesso era somente permitido se a instituição de ensino fosse cadastrada. Isto devido ao fato de que o Facebook foi criado por Mark Zuckerberg, aluno da Harvard University, e seu uso inicial era restrito aos alunos desta Universidade. Atualmente, o Facebook está em todos os lugares e pode ser acessado por meio de tablet, celular e smartphone, além dos desktops.

Qualquer pessoa que declare ter mais de 13 anos pode se tornar usuário registrado do Facebook, ou seja, no Brasil esta limitação de idade engloba os adolescentes de acordo com o Estatuto da Criança e do Adolescente - Lei No. 8.069/1990, art. 2o: "Considera-se criança, para os efeitos desta Lei, a pessoa até doze anos de idade incompletos, e adolescente aquela entre doze e dezoito anos de idade" (BRASIL, 1990).

Estudo realizado pelo Online Business School, "Social Media 2015”, mostra que a Espanha "ocupa el décimo lugar del mundo com más de 10.000.000 de usuarios en Facebook" ${ }^{4}$ (OBS, 2015, p.01). Neste contexto, inicialmente apresenta-se a realidade brasileira mostrando dados quantitativos para, então, apresentar a realidade espanhola e, consequentemente, estabelecer um paralelo no que tange aos seguintes tópicos: uso de Internet, redes sociais, exposição pública nas redes sociais e consumo.

Não se tem a pretensão de esgotar o tema, nem mesmo de reproduzir todos os dados estatísticos disponíveis. $\mathrm{O}$ estudo ora apresentado reflete a compilação por meio de técnica de pesquisa elaborada com base em documentação indireta, ou seja, pesquisa bibliográfica. Busca-se relacionar os tópicos mencionados de maneira a compor a linha dorsal de pensamento e desenvolvimento do trabalho realizado.

\subsubsection{Panorama no Brasil}

O Relatório "Pesquisa Brasileira de Mídia 2015"5 (BRASIL, 2014, p. 49-64) mostra que "Praticamente a metade dos brasileiros, 48\%, usa internet" sendo os usuários “... ficam conectados, em média, 4 h59 por dia durante a semana e 4 h24 nos finais de semana -

4 Tradução livre: 'ocupa o décimo lugar no mundo com mais de 10.000.000 de usuários no Facebook'.

5 Cabe destacar, que os resultados apresentados no Relatório "Pesquisa Brasileira de Mídia 2015” (BRASIL, 2014) foram coletados entre os dias 5 e 22 de novembro de 2014, por meio de entrevistas domiciliares pessoais face-to-face, tendo sido realizada por um conjunto de 300 entrevistadores que aplicaram 85 perguntas a 18.312 pessoas maiores de 16 anos, em 848 municípios brasileiros. 
na PBM 2014, os números eram 3h39 e 3h43 -, valores superiores aos obtidos pela televisão" (BRASIL, 2014, p. 7). São fatores impulsionadores da frequência e da intensidade de uso da Internet no Brasil, a escolaridade e a idade dos entrevistados. O Relatório aponta ainda que $72 \%$ dos usuários, com ensino superior, acessam a internet todos os dias, com uma intensidade média diária de 5 horas e 41 minutos, de $2^{\text {a }}$ a $6^{\mathrm{a}}$-feira. Para os usuários com escolaridade até a $4^{\text {a }}$ série, somente $5 \%$ utilizam todos os dias com uma intensidade média de e 3 horas e 22 minutos. Na faixa etária 16 a 25, o Relatório mostra que 65\% dos jovens se conectam todos os dias, em média 5 horas e 51 minutos durante a semana. Já na faixa etária de 65 anos ou mais, somente $4 \%$ se conectam todos os dias, em média 2 horas e 53 minutos (BRASIL, 2014, p. 7).

Os brasileiros buscam por meio da Internet informações, sendo que $67 \%$ buscam por notícias sobre temas diversos ou informaçóes de um modo geral, 67\% por diversão e entretenimento, $38 \%$ por uma forma de passar o tempo livre e $24 \%$ por estudo e aprendizagem (BRASIL, 2014, p. 49) ${ }^{6}$. O Relatório “TIC Domicílios e Empresas 2013”7 mostra que em 2013, quase a metade dos domicílios brasileiros (49\%) possuía computador, enquanto $43 \%$ tinham acesso à Internet, correspondendo a 27,2 milhóes de habitantes em números absolutos (Comitê Gestor da Internet no Brasil, 2014, p.33).

Mostra-se que a desigualdade social persiste, de modo que "na classe A, a proporção de domicílios com acesso à Internet é de 98\%; na classe B, 80\%; na classe C, 39\%; e nas classes D e E, 8\%". Nas áreas urbanas, a proporção de domicílios com "acesso à Internet é de 48\%, enquanto nas áreas rurais é de 15\%”. "Em 2013, a proporção de usuários de Internet ultrapassou, pela primeira vez, a metade da população, alcançando $51 \%(85,9$ milhões de brasileiros)" (Comitê Gestor da Internet no Brasil, 2014, p. 33).

O Relatório apresenta também que existe uma notável diferença entre as faixas etárias em termos de perfil dos usuários. "Entre os indivíduos de 10 a 15 anos a proporção de usuários chega a 75\%, atingindo $77 \%$ entre os de 16 a 24 anos. Entre as pessoas de 35 a 44 anos de idade, 47\% são usuárias de Internet, enquanto apenas 33\% das pessoas entre 45 e 49 anos e 11\% daquelas com mais de 60 anos são usuárias da rede. Em números absolutos, há mais de 45 milhóes de pessoas de 45 anos ou mais que não usam Internet. A proporção dos que usam a Internet diariamente cresceu de 53\% em 2008 para $71 \%$ em 2013" (Comitê Gestor da Internet no Brasil, 2014, p. 33).

Interessante registrar que, em 2013, os celulares são o centro das atençóes. O Relatório aponta que " $85 \%$ das pessoas com 10 anos de idade ou mais usavam telefone celular,

6 Deve-se observar que os resultados obtidos consideram respostas múltiplas à seguinte pergunta: "Por quais razóes, entre as que estão nesta lista, o(a) sr(a). usa a internet?" (BRASIL, 2014, p. 59).

7 Foram entrevistados 21.876 pessoas em 350 municípios distribuídos nas 5 regióes do Brasil (Norte, Nordeste, Sul, Sudeste e Centro-Oeste) - Tabela 2 (Comitê Gestor da Internet no Brasil, 2014, p.145146). 
totalizando 143 milhóes de brasileiros. Na classe DE esta proporção é de 69\% e na área rural é de 73\%” (Comitê Gestor da Internet no Brasil, 2014, p. 33).

No que se refere às redes sociais, o Relatório aponta que "Entre os internautas, 92\% estão conectados por meio de redes sociais, sendo as mais utilizadas o Facebook (83\%), o Whatsapp (58\%) e o Youtube (17\%)" (BRASIL, 2014, p. 62). BELLO (2012, p. 1) mostra que a partir de pesquisa da empresa F-Secure que " $86 \%$ dos brasileiros dizem se expor demais nas redes sociais". Esta situação é demonstrada visto que o Relatório TIC Domicílios e Empresas 2013 (Comitê Gestor da Internet no Brasil, 2014, p.83) aponta que "1,3 bilhôes de pessoas possui sua "própria página web" no Facebook, onde se vê e se é visto e através da qual a proximidade social, a reputação e o uso estratégico da informação desempenham papéis fundamentais". E, ainda, que "30\% dos usuários de telefone celular acessaram redes sociais a partir do aparelho; $26 \%$ compartilharam fotos, vídeos ou textos; 25\% acessaram e-mails; e 23\% baixaram aplicativos" (Comitê Gestor da Internet no Brasil, 2014, p. 163). Dados que demonstram diretamente o uso das TICs e, indiretamente, que as características de acessibilidade e disponibilidade estão presentes aos usuários.

Ainda no Brasil, a E-bit, no relatório "Webshoppers 2014” (e-bit, 2014, p.08), apresenta que em 2013 o comércio eletrônico faturou $\mathrm{R}$ \$ 28,8 bilhóes, obtendo um crescimento nominal de 28\% em relação a 2012. Já no relatório "Webshoppers 2015" tem-se que (e-bit, 2015, p.08) o comércio eletrônico brasileiro faturou R \$ 35,8 bilhóes em 2014, um crescimento nominal de $24 \%$ comparado a 2013.

\subsubsection{Panorama na Espanha}

Estudo realizado pelo Online Business School, "Social Media 2015” (OBS, 2015, p. 1), apresenta que

España cuenta con una población online de 23 millones de personas. El $73 \%$ de esta población (17 millones de usuarios) utiliza activamente las redes sociales mensualmente en 2014, y únicamente el $8 \%$ dice no tener cuenta en ninguna red. Un 73\% dice que accede a las redes desde todos los dispositivos, el $68 \%$ únicamente desde ordenador (PC o portátil), el 46\% desde Smartphone y el 21\% desde Tablet ${ }^{8}$.

PAVIA (2014, p. 66) apresenta de acordo com estudo da " 5 a oleada del Observatorio de Redes Sociales" as redes mais utilizadas na Espanha, em 2013, são: "la generalista

8 Tradução livre: 'A Espanha conta com uma população online de 23 milhóes de pessoas, sendo que 73\% desta população (17 milhóes de usuários) utiliza ativamente as redes sociais mensalmente em 2014, e somente $8 \%$ diz não possuir perfil algum. Um total de $73 \%$ indica que acessa às redes sociais a partir de diversos dispositivos, sendo que $68 \%$ somente tem acesso a partir do computador (PC ou notebook), $46 \%$ acessam a partir de smartphone e $21 \%$ a partir de tablet'. 
Facebook (83\%), el contenedor y distribuidor audiovisual Youtube (52\%) y el microbloging Twitter (42\%) que es el que ha crecido más en los últimos tres años (37\%)" . Destaca-se que o Twitter é a rede mais utilizada para o usuário "estar informado sobre temas de interés con un 44\%, mientras que en Facebook solo buscan información el 15\% de los encuestados" ${ }^{10}$. Continua PAVIA (2014, p. 30) apresentado que

En 2013 una cifra internacional da cuenta del futuro del consumo digital: el 63\% de los niños menores de 8 años usa el smartphone, y entre los menores de 2 años el uso es del 38\%, casi 30 puntos por encima de los datos de 2011, según datos de Common Sense Media, una ONG dedicada a empoderar niños y familias como ciudadanos digitales ${ }^{11}$.

RUIZ e RÍO (2009, p. 87) apresentaram que "En España, según datos de la Fundación Orange, en diciembre de 2008 el 73,7\% de los internautas mayores de 15 ańos disponía de una cuenta en alguna red virtual"12. Em 2009, considerando a idade dos entrevistados (18 a 25 anos) foi apontado que "Facebook sea la red preferida (un 87,4\% está conectado a ella). Tuenti ocupa el segundo lugar, con un $44 \%$ de los encuestados conectado a ella"13 (RUIZ e RÍO, 2009, p. 95). PAIVA (2014, p. 30) destaca também que

Ya en 2009, un estudio de Demoscopia y la Fundación Pfizer dibujaba en España una familia altamente tecnologizada, con preferencia del computador en las habitaciones de los hijos y un uso del teléfono móvil entre ellos de casi un $90 \%$ de los casos, que llegaba casi al $99 \%$ en el uso de Internet $^{14}$.

O uso preferencial das redes sociais, na Espanha, possui os seguintes motivos: "compartir experiencias con los amigos $(82,8 \%)$, saber lo que dicen mis amigos de las fotos que subo y las experiencias que vivimos (51\%), hacer nuevos amigos $(45,6 \%)$ "15 (COLÁS et

9 Tradução livre: 'Facebook (83\%), Youtube (52\%) e Twitter (42\%), o qual foi o que mais cresceu nos últimos 3 anos (37\%)'.

10 Tradução livre: 'Twitter é a rede mais utilizada para o usuário estar informado sobre temas de interesse com 44\%, enquanto que no Facebook buscam informaçáo somente $15 \%$ dos entrevistados'.

11 Traduçấo livre: 'Em 2013 o aporte internacional do futuro do consumo digital mostra que: 63\% das crianças menores de 8 anos usam smartphone e entre os menores de 2 anos o uso é de $38 \%$, quase 30 pontos acima dos dados de 2011, de acordo com informaçóes do Common Sense Media, uma ONG dedicada a capacitar crianças e famílias como cidadãos digitais'.

12 Tradução livre: 'Na Espanha, segundo informaçóes da Fundação Orange, em dezembro de 2008, 73,7\% dos internautas maiores de 15 anos dispunha de um perfil em alguma rede social'.

13 Tradução livre: 'Facebook é a rede preferida com 87,4\% dos usuários. O Twitter ocupa o segundo lugar, com $44 \%$ dos entrevistados conectados'.

14 Tradução livre: 'Já em 2009, um estudo de Demografia da Fundação Pfizer mostrava que na Espanha uma família altamente tecnológica, com preferência do computador nos quartos de seus filhos e uso do celular entre eles de quase $90 \%$ dos casos, atingiu quase $99 \%$ do uso da Internet'.

15 Tradução livre: "compartilhar experiências com os amigos (82,8\%), saber o que dizem meus amigos das fotos que por mim são postadas e sobre as experiências que vivemos (51\%), fazer novos amigos $(45,6 \%)$ ". 
al., 2013, p. 19). RUIZ e RÍO (2009, p.97, tradução nossa) mostram que 88,1\% dos jovens na Espanha publicam dados pessoais reais em seus perfis nas redes sociais, sem que se percebam diferenças significativas entre homens e mulheres. Os autores destacam que "9,4\% opta por mezclar datos reales con datos ficticios y el 2,5\% reconoce la falsedad de la información que aparece en sus perfiles"16.

Em estudo realizado com jovens entre 14 e 20 anos, da Província de Rioja, FERNÁNDEZ (2014, p. 17) ${ }^{17}$ mostra que 50\% dos jovens entrevistados caracterizam-se por um perfil reservado, ou seja, possuem "Alta precaución de acceso a sus datos personales e declara no identificarse sobre cosas personales" ${ }^{18}$. Em relação aos dados pessoais que são apresentados nos perfis das redes sociais, o estudo mostra que $97,7 \%$ divulgam seu nome, $92,9 \%$ divulgam a data de aniversário, 85,4\% postam fotos pessoais e 21,6\% postam vídeos pessoais (FERNÁNDEZ, 2014, p. 18).

Em referência a privacidade, "Los jóvenes conocen los riesgos de Internet pero se produce lo que denominamos la 'excepción de la privacidad'." 19 (FERNÁNDEZ, 2014, p. 20). Continua a autora, mostrando que

$79 \%$ de menores espańoles de 14-16 años no ve amenazada su privacidad en las redes sociales. Los mismos que declaran que conocen a alguien que ha tenido experiencias contrarias a su privacidad (45\%) y que manifiestan ser conscientes de que los datos que se cuelgan en la red pueden ser vistos por otras personas $(97 \%)$, e incluso, grabados $(82,7 \%)^{20}$.

No que se refere ao comércio eletrônico, de acordo com relatório apresentado pela Comisión Nacional de los Mercados y la Competencia (CNMC, 2014, p. 3), "el comercio electrónico en España alcanzó un volumen de negocio de 3.893,5 millones de euros, lo que supone un 22,2\% más que en el mismo trimestre de 2013; con un total de 56,6 millones de operaciones" ${ }^{21}$.

16 Tradução livre: '9,4\% opta por mesclar dados reais com dados fictícios e 2,5\% reconhece a falsidade das informaçôes que aparecem nos seus perfis'.

17 Tamanho da Amostra $=400$ pessoas. Erro amostral $=+5 \%$ com nível de confiança $=95 \%$. O tamanho da população jovem de 14 a 20 anos é desconhecido, portanto, estimada em 20.000 habitantes.

18 Traduçáo livre: 'Alta cautela de acesso aos seus dados pessoais e declara que não se identifica sobre coisas (fatos) pessoais'.

19 Traduçấo livre: Os jovens conhecem os riscos da Intenet mas se produz o que denominamos de exceção à privacidade'.

20 Traduçấo livre: 79\% das crianças espanholas de 14 a16 anos náo se sentem ameaçadas em sua privacidade nas redes sociais. Os mesmos jovens que declaram conhecem alguém que tenha tido experiências contrárias à privacidade $(45 \%)$ e se manifestam ser conscientes de que os dados que são publicados na rede podem ser visto por outras pessoas (97\%), e até mesmo gravados (82,7\%)'.

21 Tradução livre: 'O comércio eletrônico na Espanha alcançou um volume de negócios na ordem de $3.893,5$ milhóes de euros, o que demonstra um acréscimo de 22,2\% comparado ao mesmo trimestre de 2013, com um total de 56,6 milhôes de operaçóes'. 
A Uniấo Européia ocupa o $1^{\circ}$. lugar como destino dos recursos aportados pela Espanha aportando 89,4\% dos recursos. Os países pertencentes a C.E.M.E.A. (países da Europa Central, Oriente Médio e África, entre os quais se incluem Suíça, Rússia, África do Sul, Turquia e Arábia Saudita) estão em 20. lugar com 4,3\% e os Estados Unidos da América se encontram no $3^{\circ}$. lugar, representando 4,1\% (CNMC, 2014, p. 10, tradução nossa).

\subsubsection{Considerações: Brasil e Espanha}

As diferenças existem. E semelhanças também. Ocorre que para o Brasil não foram encontrados estudos ou relatórios que apresentem detalhadamente as características da exposição pública realizada por meio das redes sociais, tal qual existe na Espanha.

Segue-se, portanto, com uma comparação entre as variáveis passíveis de se estabelecer uma visão geral. Os dados mostram que há uma maior concentração de usuários jovens no Brasil e que estes passam mais tempo conectados que os jovens espanhóis. São 27 horas no Brasil e 23,8 horas na Espanha (PAVIA, 2014, p. 83). PAVIA (2014, p. 83) mostra que

En Brasil, la proporción de usuarios de Internet que pasa más tiempo conectado es la de las edades de 25 a 34 ańos. Los datos son muy similares para los grupos de edad inmediatamente superior e inmediatamente por debajo de ese -15-24 años y 35-44 años. En España, los internautas más jóvenes no pasan mucho tiempo en línea, un promedio de 16,4 horas/mes para los de 15 a 24 años. Las personas de 25-34 años pasan prácticamente al mismo tiempo conectado a los de 35 a 44 años: 24,9 horas/mes en el primer grupo y de 25,4 horas/mes en el segundo ${ }^{22}$.

PAVIA (2014, p. 84) corrobora que

En España, la división entre los grupos de edad tiene diferencias menos dramáticas... Uno con la mayor concentración de usuarios de Internet es el de 34 a 44 años, con el 23\% del total. Si sumamos el porcentaje de usuarios de Internet de más edad, se observa que el 51,4\% de los conectados en el país tienen más de 34 años. Es decir, la situación se invierte cuando se compara con el brasileño ${ }^{23}$.

22 Tradução livre: 'No Brasil, a proporcão de usuários de Internet que passa mais tempo conectado é a faixa etária de 25 a 34 anos. Os dados são muito similares para as faixas etárias imediatamente superior e inferior, ou seja, 15 a 24 anos e 35 a 44 anos. Na Espanha, os internautas mais jovens não passam muito tempo conectados, com média de 16,4 horas/mês para a faixa etária de 15 a 24 anos. As pessoas entre 25 e 34 anos passam praticamente o mesmo tempo conectado que os internautas da faixa etária de 55 a 44 anos: 24,9 horas/mês para o primeiro grupo e 25,4 horas/mês para o segundo grupo, respectivamente’.

23 Tradução livre: 'Na Espanha, a divisão entre os grupos apresenta diferenças menos significativas.,. O grupo com a maior concentração de usuários Internet é a faixa etária de 34 a 44 anos, com 23\% do total. 
E, ainda que "En ambos países, el crecimiento anual de la audiencia online es similar, a finales de 2013 estava en 9\%"24 (PAVIA, 2014, p. 84). Observa-se uma característica comum quando se trata da exposição nas redes sociais, ou seja, a necessidade de interagir com seus pares ou "amigos".

A estrutura comportamental das redes sociais é suportada pela arquitetura de visibilidade, permitindo que a exposição seja concretizada e que as pessoas se mostram a todos e, também, possam ser observadas. O Facebook implementa tal estrutura comportamental organizando sub-estruturas dentro da grande estrutura. Cabe ao usuário a dimensão da sua própria rede sem que se possa contabilizar ou vislumbrar as reais fronteiras de cada sub-estrutura ou, mesmo, conhecer todos os relacionamentos e derivaçóes existentes a partir de cada usuário.

As perspectivas são positivas, no que se refere ao comércio eletrônico, seja no Brasil ou na Espanha, porém não se pode deixar que lado que a aceitação ampla do processo de compra online ainda depende da superação de vários tipos de obstáculos como barreiras tecnológicas, culturais e organizacionais. Como problemas e dificuldades, os consumidores brasileiros apontaram, em 2010, que os principais motivos para os brasileiros não comprarem na Internet são: 30\% fator segurança, 18\% medo de não receber o produto, $16 \%$ possíveis problemas com troca de produtos e $15 \%$ dos consumidores que náo querem pagar frete (e-commerce News, 2010, p. 1). Ainda restam alguns gaps no que se referem à: segurança na transação eletrônica, falta de confiança dos usuários em relaçáo à segurança no sistema da compra eletrônica e necessidade de garantia da privacidade.

A seguir são apresentados os mecanismos de exposição, os quais são amplamente utilizados nos sites de comércio eletrônico e redes sociais, visando demonstrar como e por que tais mecanismos aumentam a vulnerabilidade do consumidor.

\subsection{Mecanismos de Recomendação}

Entende-se por mecanismo de recomendação as ferramentas ou recursos para a seleção e classificação, avaliaçóes, críticas e sugestôes de produtos e/ou serviços similares. Estes mecanismos visam objetivamente oferecer avaliaçóes, prediçóes e recomendaçóes por meio de indicadores, quais sejam: notas, pontuação em escalas, estrelas, cores, barras, entre outros. São mecanismos comparativos e estabelecem relação qualitativa, por exemplo, quando é apresentada uma nota a um produto entre 0 e 10 , sabe-se o valor da nota alcançada pelo produto e, ainda, o número de usuários-consumidores que fizeram suas avaliaçóes.

Ao somar a porcentagem de usuários de Internet mais velhos, observa-se que $51,4 \%$ dos usuários no país tem mais de 34 anos. Isto significa que a situação se inverte quando se compara aos brasileiros'.

24 Tradução livre: 'Em ambos os países, o crescimento anual da audiência online é similar, visto que ao final de 2013 estava em 9\%’. 
Para RICCI et al. (2011, p. 1) "Recommender Systems (RSs) are software tools and techniques providing suggestions for items to be of use to a user. The suggestions relate to various decision-making processes, such as what items to buy, what music to listen to, or what online news to read." 25 . Complementam os autores o entendimento de "item", definindo como sendo: "Item is the general term used to denote what the system recommends to users." ${ }^{26}$. Sob uma ótima ampla, um item pode ser qualquer produto ou serviço que possa interessar a alguém.

RESNICK e VARIAN (1997, p. 56) apresentam o conceito de sistemas de recomendação, a saber: "Recommender systems assist and augment this natural social process. In a typical recommender system people provide recommendations as inputs, which the system then aggregates and directs to appropriate recipients." ${ }^{27}$.

Os sistemas de recomendaçáo ampliam a capacidade deste tipo de procedimento já existente entre os seres humanos por meio das relaçóes sociais. O primeiro sistema de recomendação, denominado Tapestry, foi proposto por GOLDBERG et al. (1992, p. 1) tendo sido estabelecido o conceito de "filtragem colaborativa", a qual designa um tipo de sistema específico que permite a filtragem de informação realizada com o auxilio humano, ou seja, necessita da colaboração entre os grupos de interessados. Os autores utilizam o termo sistema para designar um programa de computador ou software.

Da década de 90 para os dias atuais, os sistemas de recomendaçáo evoluíram, são mais complexos e independem da intervenção humana para serem aplicados a um conjunto de dados.

É importante, entender que nestes sistemas as pessoas fornecem suas recomendaçôes como entradas (input) e o sistema calcula, agrega, direciona e apresenta, aos indivíduos considerados interessados, os resultados obtidos, os quais podem ser visualizados de maneiras variadas (como já mencionado, por meio de notas, pontuação em escalas, estrelas, cores, barras, entre outros). O desafio dos sistemas computacionais, a partir do grande volume de dados introduzidos pelos usuários e coletados em site, é realizar o matching adequado e mais provável (estudo probabilístico) entre os que fazem as recomendaçóes e os que recebem a recomendação. Descobrir as relaçôes de interesse é a parte "inteligente" do sistema. São utilizadas técnicas de Descoberta do Conhecimento em Bases de Dados, assim definido por FAYYAD et al. (1996, p. 37):

25 Tradução livre: 'Sistemas de recomendação (SRs) são ferramentas de software e técnicas que fornecem sugestóes de itens que podem ser úteis para um usuário. As sugestốes relacionam-se aos diversos processos de tomada de decisão, por exemplo, quais itens para comprar, qual música para escutar ou quais notícias na Internet para ler'.

26 Tradução livre: 'Item é o termo genérico utilizado para designar o que o sistema recomenda ao usuário'.

27 Tradução livre: 'Sistemas de recomendação auxiliam e ampliam este processo social natural. Em um típico sistema de recomendação as pessoas fornecem recomendaçóes como entradas, as quais são agregadas e direcionadas pelo sistema ao receptor apropriado'. 
"Across a wide variety of fields, data are being collected and accumulated at a dramatic pace. There is an urgent need for a new generation of computational theories and tools to assist humans in extracting useful information (knowledge) from the rapidly growing volumes of digital data. These theories and tools are the subject of the emerging field of knowledge discovery in databases" 28 .

Existem várias classificaçóes para os mecanismos e sistemas de recomendação, de acordo com as estratégias utilizadas para recomendar e com as técnicas de filtragem aplicadas sobre os dados com a finalidade de gerar resultados de recomendação. De acordo com CAZELLA et al. (2010, p. 15-23) pode-se classificá-los em:

- Recomendação colaborativa: recomendação baseada em memória, ou seja, os sistemas armazenam dados e ofertam recomendaçóes orientadas aos usuários ou recomendaçóes orientadas aos itens (produtos e serviços). Estes mecanismos têm por base o estabelecimento de modelos (matemáticos, estatísticos ou probabilísticos) ou em conjuntos de regras pré-estabelecidas;

- Recomendação por conteúdo: nestes casos, os sistemas utilizam métodos de representação de conteúdo e estabelecem similaridades entre, por exemplo, produtos para poder recomendá-los. Estes mecanismos utilizam técnicas baseadas em modelos probabilísticos, aprendizagem de máquina, árvores de decisão e seleção de atributos;

- Recomendação por conhecimento: os sistemas utilizam métodos de representação de conhecimento e resolução de inferências. Nestes casos são aplicados métodos baseados em conjuntos de restriçóes e exemplos de referência;

- Recomendação híbrida: combinam os mecanismos anteriores de modo a oportunizar o melhor de cada um deles, visando sistemas inteligentes de aprendizagem e técnicas refinadas de análise de textos.

O IBM Knowledge Center ${ }^{29}$ apresenta três categorias de mecanismos de recomendação, a saber:

- Mecanismo de Preferência: gera recomendaçóes utilizando algoritmos de filtragem colaborativos tendo por base as classificaçóes de itens introduzidas no sistema diretamente pelos usuários;

28 Tradução livre: 'Em várias áreas de atuação, os dados estão sendo coletados e acumulados em um ritmo dramático. Há uma necessidade urgente de uma nova geração de teorias e ferramentas computacionais para ajudar os seres humanos a extraírem informaçôes úteis (conhecimento) do rápido crescente volume de dados digitais. Estas teorias e ferramentas são o tema do campo emergente da Descoberta de Conhecimento em Bases de Dados'.

29 Disponível em <http://infolib.lotus.com/resources/portal/8.0.0/doc/pt_br/PT800ACD001/pzn/pzn_ likeminds_recommendation_engines_3.html > Acesso em 15 mai. 2015. 
- Mecanismo de Sequência de Cliques: gera recomendaçóes baseadas nas açóes dos usuários quando eles navegam por um site. Utiliza-se do histórico de "cliques" do usuário durante as visitas ao site, utilizando "marcadores" dos itens que são visualizados, selecionados (por cliques) e incluídos nos carrinhos de compras;

- Mecanismo de Afinidade de Itens: gera recomendaçóes com base no histórico da atividade de navegação no site do usuário. Deste modo, o sistema pode relacionar um produto atualmente selecionado com um segundo produto que o usuário provavelmente gostaria de comprar, gerando uma associação entre produtos e/ou serviços.

Os mecanismos de recomendação apresentados anteriormente não esgotam o assunto, mas permitem o entendimento do modo como tais sistemas podem ser construídos a partir da entrada de dados, fornecidos pelos usuários, de maneira que outros usuários recebam os resultados e, assim, podem-se estabelecer desde modelos de decisão de consumo até métricas de avaliação (offline ou online).

Outro ponto relevante, é que os sistemas de recomendação também fornecem avaliaçôes sobre os avaliadores, de modo a gerar confiança e fidelizar o usuário-consumidor. Além disto, questóes como: segurança das informaçóes, privacidade e interpretabilidade dos dados fornecidos e resultados obtidos; são pontos relevantes e que merecem estudo.

RESNICK e VARIAN (1997, p. 57) afirmam que os mecanismos de recomendação remetem a dois pontos interessantes, a saber: a partir do estabelecimento do perfil de interesse é fácil percorrer as avaliaçôes de consumo indicadas por outras pessoas e, ainda, se ninguém fornecer recomendaçôes, os próprios sistemas podem fornecer avaliaçôes positivas aos seus produtos e serviços e avaliaçóes negativas aos seus concorrentes. Eis o confronto com o princípio da boa-fé.

Acredita-se que as pessoas que recomendam fazem uma triagem prévia do produto ou serviço, indicando o que será consumido. E os mecanismos de recomendação fazem uma triagem posterior, agregando informaçóes sobre o que foi efetivamente consumido. Deve-se ponderar, tal qual ANDERSON (2006, p. 121), que "os filtros já não mais desempenham o papel de porteiros e passam a atuar como assessores. Em vez de prever a preferência, os pós-filtros como o Google, medem a preferência”.

O sucesso dos mecanismos de recomendação está na força dos usuários que voluntariamente fornecem suas indicaçóes, mas acredita-se que muito há para ser explorado. São muitas as vantagens, visto que "as recomendaçóes têm todo o poder de gerar demanda, mas a custo praticamente zero" (ANDERSON, 2006, p. 108). Além disto, os mecanismos se tornaram táo comuns que desde sites de passagens aéreas até sites de livros utilizam 
cada vez mais fortemente este tipo de indicação. Para os consumidores resta decidir quando e como aceitar as recomendaçóes e, ainda, se desejam envolver-se como avaliadores.

As recomendaçôes passaram a influenciar padróes de consumo, fazendo com que a credibilidade e reputação de produtos e/ou serviços aumente. Cria-se um ciclo de retroalimentação (feedback) e a exposição online do usuário se mantém. O boca a boca do mundo real agora habita o mundo digital e está a cada clique mais próximo de relacionar o interesse do interessado, seja este o usuário, o consumidor ou o internauta.

\section{Vulnerabilidade do Consumidor Frente à Sociedade de Exposição}

Ao se expor, o consumidor revela seus dados, interesses, gostos, hábitos, entre outros. $\mathrm{E}$, a crescente necessidade do consumidor em estar informado, permite que as recomendaçóes de outras pessoas (desconhecidas e comuns) tenham não somente a dimensão do interesse, mas a da influência sobre a decisão final do consumidor. Isto ocorre quando se consulta um site ou web page para comprar eletronicamente, consultar preços ou simplesmente realizar uma busca por informaçóes.

A tríade consumir-expor-recomendar leva ao estudo da vulnerabilidade do consumidor frente à sociedade de exposição e aos mecanismos de recomendação, visto que tais métodos "podem influenciar o comportamento do consumidor por meio de estímulos voltados a atingir o seu inconsciente, tolhendo suas possibilidades de resistência e impossibilitando qualquer defesa, o que aumenta consideravelmente a sua situação de vulnerabilidade", como apontado por TAMBARA (2014, p. 90).

DOOLEY (2012, p. 1) afirma que "95\% de nossos pensamentos, emoçóes e de nosso aprendizado ocorrem sem que estejamos conscientes". Continua o autor explicando que são muitas as técnicas e maneiras de influenciar a mente do consumidor. A frase: "Um diamante é para sempre" é muito conhecida. E como o autor comenta "este é um bom exemplo de anúncio que, escrupulosamente, evita dar sugestôes de dinheiro" (DOOLEY, 2012, p. 10).

O aumento da vulnerabilidade é preocupação tratada na Resolução N. ${ }^{0} 39 / 248^{30}$, de 16 de abril de 1985, sendo que a ONU reconhece abertamente um conjunto de desigualdades que colocam o consumidor em condição de vulnerabilidade:

“...recognizing that consumers often face imbalances in economic ter$\mathrm{ms}$, educational levels, and bargaining power; and bearing in mind that consumers should have the right of access to non-hazardous products, as

30 ONU - Organização das Nações Unidas. Resoluçấo No. 39/248. Disponível em <http://www.un.org/ documents/ga/res/39/a39r248.htm> Acesso em 15 mai. 2015. 
well as the right to promote just, equitable and sustainable economic and social development..."31.

Este posicionamento da ONU foi fortalecido por ALMEIDA (2006, p. 25), apontando que "Hoje há consenso universal acerca da vulnerabilidade do consumidor. Não se questiona mais sobre esse ponto. Em todos os países do mundo ocidental já há esse reconhecimento".

No Brasil, a Constituição Federal (BRASIL, 1988) positiva por meio do art. 5o, inciso XXXII, a defesa do consumidor, estando esta defesa enquadrada nos Direitos e Garantias Fundamentais. A vulnerabilidade do consumidor está prevista, infraconstitucionalmente, no inciso I do art. $4^{\circ}$ do Código de Defesa do Consumidor (CDC), Lei No. 8.078/90 (BRASIL, 1990):

Art. 4o A Política Nacional das Relaçóes de Consumo tem por objetivo o atendimento das necessidades dos consumidores, o respeito à sua dignidade, saúde e segurança, a proteção de seus interesses econômicos, a melhoria da sua qualidade de vida, bem como a transparência e harmonia das relaçóes de consumo, atendidos os seguintes princípios:

I - reconhecimento da vulnerabilidade do consumidor no mercado de consumo.

E, ainda, tem-se que o CDC, em seu inciso III do art. 60 (BRASIL, 1990), apresenta que "São direitos básicos do consumidor: (...) III - a informação adequada e clara... prescricional de cinco anos do art. 27 do CDC.”. Cabe questionar: Como o consumidor pode ter certeza que os mecanismos de recomendação disponibilizam informação clara e adequada? Eis novamente o princípio da boa-fé.

Assim, reconhece-se que o consumidor está em desigualdade de condiçóes informacional, técnica, econômica, social, ambiental, jurídica e política (MARQUES, 1999, p. 147-149) (MORAES, 1999, p. 115 e ss.).

O interesse do estudo recai sobre a desigualdade de informaçóes, reforçada por MARQUES (1999, p.147-149), de modo que "O comprador não possui conhecimentos específicos sobre o objeto que está adquirindo e, portanto, é mais facilmente enganado quanto às características do bem ou quanto à sua utilidade”. Neste sentido, SILVA NETO (2013, p. 77-78) aponta que:

31 Tradução livre: “... reconhecendo que os consumidores sempre enfrentam desigualdades em termos econômicos, em níveis educacionais, em poder de negociação, e tendo em mente que os consumidores deveriam ter o direito de acesso a produtos de natureza náo duvidosa, assim como o direito de promover justiça, eqûidade e o desenvolvimento social e econômico sustentáveis...”. 
O consumidor deverá ter acesso à informação necessária a respeito das características do produto e do contrato, bem como à informação sobre como essas características podem afetar seu interesse pessoal e sua individualidade. Mais do que isso, o direito à educação para o consumo compreende a obrigaçáo de que o consumidor seja informado a respeito dos conteúdos efetivos das informaçóes, de forma clara e acessível. O dever de informação não se esgota na informação correta, só sendo adequadamente cumprido se a informação, além de correta, for clara e acessível. Já no que diz respeito à liberdade de escolha, o consumidor deve ter liberdade de optar, entre as várias escolhas possíveis, por aquela que ele entenda ser a que melhor atende a seus interesses, o que só é possível se a liberdade formal vier acompanhada de informação adequada.

Desta forma, verifica-se que os consumidores, vulneráveis, tendem a confiar nos mecanismos de recomendação por meio do recebimento de informaçóes claras e adequadas. Porém, tais mecanismos podem influenciar o poder de decisão do consumidor e, consequentemente, comprometer sua dignidade e capacidade de decisáo. Os consumidores que são influenciados pelos mecanismos de recomendação se equiparam aos consumidores hipervulneráveis.

Para defender o consumidor, o CDC leciona em seu capítulo II, art. $4^{\circ}$, sobre a Política Nacional de Relações de Consumo, que descreve (BRASIL, 1990):

Art. $4^{\circ} \ldots$

III - harmonização dos interesses dos participantes das relações de consumo e compatibilização da proteção do consumidor com a necessidade de desenvolvimento econômico e tecnológico, de modo a viabilizar os princípios nos quais se funda a ordem econômica (art. 170, da Constituição Federal), sempre com base na boa-fé e equilíbrio nas relaçôes entre consumidores e fornecedores;

VI - coibição e repressão eficientes de todos os abusos praticados no mercado de consumo, inclusive a concorrência desleal e utilização indevida de inventos e criaçóes industriais das marcas e nomes comerciais e signos distintivos, que possam causar prejuízos aos consumidores.

Busca-se, por meio da política pública de harmonização de interesses dos sujeitos da relaçáo de consumo, uma harmonização diretamente relacionada com o balanceamento e ponderação dos interesses na relação. Entende-se que o equilíbrio necessário para que esta harmonização seja efetiva é de difícil aplicação. Harmonia nas relaçóes consumeristas é algo que novamente remete ao princípio da boa-fé. 
Finalmente, entende-se que os mecanismos de recomendação infringem o CDC em seu art. $6^{\circ}$ que consagra como direito básico do consumidor, "a educação e divulgação sobre o consumo adequado dos produtos e serviços, assegurados à liberdade de escolha e a igualdade nas contrataçóes". E, ainda, deve-se retomar aos incisos III e IV, os quais formam a base legal da construçáo doutrinária conhecida como "princípio da proteçáo da confiança”.

\section{Conclusões}

$\mathrm{O}$ artigo trata o usuário da Internet e das redes sociais que diante do Código de Defesa do Consumidor equipara-se ao consumidor e, portanto, questiona a exposição pública deste usuário que faz crescer a vulnerabilidade do consumidor. Apresenta-se uma visáo da realidade brasileira e espanhola no que concerne à Internet, redes sociais, sociedade de exposição e consumo. São analisados os mecanismos de recomendação utilizados, pelos sites e redes sociais, para influenciar o poder de decisão do consumidor.

Na atualidade, LÉVY (2007, p. 14) mostra que "mexer-se não é mais deslocar-se de um ponto a outro da superfície terrestre, mas atravessar universos de problemas, mundos vividos, paisagens dos sentidos" e, portanto, tudo que se refere a cada indivíduo (usuário e consumidor) também se refere ao ciberespaço, visto que a sociabilidade se realiza neste espaço sem fronteiras ou demarcaçóes. As redes sociais são meio e não fim.

Os sistemas de recomendação contam com a disponibilidade dos usuários em fornecer dados, aplicando técnicas capazes de processar automaticamente as avaliaçóes de uma grande quantidade de usuários e consumidores. A estrutura da rede social associada à exposição confere aos seus usuários o caráter lúdico e divertido, mas também permite transmitir maior confiança e fidelidade ao usuário. A associação entre redes sociais e mecanismos de recomendação deve ser olhada cuidadosamente pelo consumidor que deseja tanto tomar uma decisão quanto conhecer produtos e serviços ou, ainda, comparar preços ou buscar por informaçóes.

Os consumidores, vulneráveis, tendem a confiar nos mecanismos de recomendação por meio do recebimento de informaçóes claras e adequadas. Porém, tais mecanismos podem influenciar o poder de decisão do consumidor e, consequentemente, comprometer sua dignidade. Conclui-se que o excesso de informaçáo mostra-se atrelado ao excesso de exposição e este elo torna-se forte à medida que a vulnerabilidade do consumidor é aumentada.

A tríade consumir-expor-recomendar somente será forte e confiável se a ela se unir o princípio da boa-fé. Consumidor consciente de que a exposição pode levar a resultados não adequados, atuará nos mecanismos de recomendação de forma séria e utilizará de mecanismos de denúncia, caso as recomendaçóes não correspondam à verdade. Deve-se 
ter em mente que a lei protege a confiança que o consumidor naturalmente deposita na informação recebida, necessitando que essa informação seja clara e adequada e, finalmente, visando que o consumidor faça suas próprias escolhas.

\section{Referências}

ALMEIDA, João Batista de. A proteção jurídica do consumidor. 5. ed. rev. atual. e ampl. São Paulo: Saraiva, 2006.

ANDERSON, Chris. A Cauda Longa. Tradução: Afonso Celso da Cunha Serra. 5a ed. Rio de Janeiro: Elsevier, 2006.

BELLO, Bruno Iacona de. $86 \%$ dos brasileiros dizem se expor demais em redes sociais. Disponível em <http://www.superdownloads.com.br/materias/6392-86-brasileirosdizem-se-expor-demais-redes-sociais.htm> Acesso em 15 mai. 2015.

BRASIL. Presidência da República. Secretaria de Comunicaçáo Social. Pesquisa brasileira de mídia 2015: hábitos de consumo de mídia pela população brasileira. Brasília: Secom, 2014.

BRASIL. Lei No. 8.078/1990 - Código de Defesa do Consumidor (CDC). Brasília, Senado Federal, 1990. Disponível em <http://www.planalto.gov.br/ccivil_03/leis/18078. htm> Acesso em 15 mai. 2015.

BRASIL. Lei No. 8.069/1990 - Estatuto da Criança e do Adolescente. Brasília, Senado Federal, 1990. Disponível em <http:/www.planalto.gov.br/ccivil_03/Leis/18069. htm> Acesso em 15 mai. 2015.

BRASIL. Constituição da República Federativa do Brasil. Brasília, Senado Federal, 1988. Disponível em <http://www.planalto.gov.br/ccivil_03/constituicao/constituicaocompilado.htm> Acesso em 15 mai. 2015.

BUENO, Silveira. Minidicionário da Língua Portuguesa. 2a ed. São PauloÇ FTD, 2007.

CAZELLA, Sílvio César; NUNES, Maria Augusta S. N.; REATEGUI, Eliseo Berni. A Ciência da Opinião: Estado da arte em Sistemas de Recomendação. Capítulo 1. In XXX Congresso da Sociedade Brasileira de Computação, 2010, Belo Horizonte. Disponível em <http://200.17.141.213/ - gutanunes/hp/publications/JAI4.pdf> Acesso em 15 mai. 2015.

COLÁS, Pilar; GONZÁLEZ, Teresa, PABLOS, Juan de. Juventud y redes sociales: Motivaciones y usos preferentes. Comunicar, No. 40, Vol.20, 2013, p.15-24.

Comitê Gestor da Internet no Brasil. Pesquisa sobre o Uso das Tecnologias da Informação e da Comunicação no Brasil: TIC Domicílios e Empresas 2013, Coordenação executiva e editorial/Alexandre F. Barbosa. São Paulo:Comitê Gestor da Internet no Brasil, 2014. 
CNMC - Comisión Nacional de los Mercados y la Competencia. Informe sobre el Comercio Electrónico en Esnpaña a través de Entidades de Medios de Pago. ESTAD/ CNMC/0002/15, 2014. Disponível em <http://telecos.cnmc.es/informes-comercio -electronico> Acesso em 15 mai. 2015.

DAL BELLO, Cíntia. Visibilidade, Vigilância, Identidade e Indexação: a questão da privacidade nas redes sociais digitais. O Estatuto da Cibercultura no Brasil. LOGOS 34, Vol.34, No01, $1^{\circ}$ semestre, 2011, p.139-151.

DOOLEY, Roger. Como Influenciar a Mente do Consumidor: 100 maneiras de convencer os consumidores com técnicas de neuromarketing. Trad. Luciene Scalzo. São Paulo: Elsevier, 2012.

e-bit. Webshoppers 2014. Disponível em: <http://www.ebit.com.br/webshoppers> Acesso em 15 mai. 2015.

e-bit. Webshoppers 2015. Disponível em: <http://www.ebit.com.br/webshoppers> Acesso em 15 mai. 2015.

e-commerce News. Motivos que levam o consumidor a não comprar pelo e-commerce. Disponível em <http://ecommercenews.com.br/destaques/motivos-que-levam-oconsumidor-a-nao-comprar-pelo-e-commerce> Acesso em 15 mai. 2015.

ECHEBURÙA, Enrique; CORRAL, Paz de. Adicción a las nuevas tecnologías y a las redes sociales em jóvenes: un nuevo reto. ADICCIONES, Vol. 22, No. 2, 2010, p.91-96.

FAYYAD, Usama; PIATETSKY-SHAPIRO, Gregory; SMYTH, Padhraic. From Data Mining to Knowledge Discovery in Databases. American Association for Artificial Intelligence, AI Magazine, Vol. 17, No. 3, 1996, p.37-54.

FELDMAN, Ronen; SANGER, James. The Text Mining Handbook: Advanced Approaches in Analyzing Unstructured Data, 2007.

FERNÁNDEZ, Carmen Sabater. La Vida Privada en la Sociedad Digital. La exposición pública de los jóvenes en internet. Aposta, Revista de Ciencias Sociales, No 61, Abril, Mayo y Junio, 2014, p.1-32.

FREITAS, Cinthia Obladen de Almnedra. Redes Sociais: Sociedade Tecnológica e Inclusão Digital. In: Marcos Wachowicz. (Org.). Direito da Sociedade da Informação \& Propriedade Intelectual. 1ed.Curitiba: Juruá, v. 1, 2012, p. 43-65.

GOLDBERG, David, NICHOLS, David, OKI, Brian. M., TERRY, Douglas. Using collaborative filtering to weave an information tapestry. Communication ACM 35, 12, Dec., 1992, p. 61-70.

GREENFIELD, Adam. Everyware: the dawning age of ubiquitous computing. AIGA, New Riders, 2006. 
JENKINS, Henry. Fans, Bloggers and Gammers: exploring participatory culture. New York: New York University Press, 2006.

LÉVY, Pierre. A Inteligência Coletiva: por uma antropologia do ciberespaço. São Paulo: Loyola, 2007.

MARQUES, Cláudia Lima. Contratos no Código de Defesa do Consumidor: o novo regime das relaçóes contratuais. 3a . Edição Revisada, Atual e Ampliada. São Paulo: Editora Revista dos Tribunais, 1999.

MARTELETO, Regina Maria. Análise de redes sociais: aplicação nos estudos de transferência da informação. Ciência da Informação, Brasília, v. 30, n. 1, jan./abr. 2001, p. 71-81.

MORAES, Paulo Valério Dal Pai. Código de defesa do consumidor: no contrato, na publicidade, nas demais práticas comerciais. Porto Alegre: Síntese, 1999.

OBS - Online Business School. Social Media 2015. 2015. Disponível em <http://www. obs-edu.com/noticias/estudio-obs/espana-aumenta-el-numero-de-usuarios-activos -en-redes-sociales-en-2014-y-llega-los-17-millones/> Acesso em 15 mai. 2015.

PAVIA, Carme Ferré. El uso de las redes sociales: ciudadanía, política y comunicación. La investigación en España y Brasil. Bellaterra: Institut de la Comunicació (In-COMUAB), Universitat Autònoma de Barcelona, 2014.

PRENSKY, Marc. Digital Natives, Digital Immigrants. On the Horizon, MCB University Press, Vol. 9, No. 5, 2001, p. 1-6.

RECUERO, Raquel. Redes Sociais na Internet: Consideraçôes Iniciais. E Compós, Vol. 2, 2005, p. 1-23. Disponível em <http://www.compos.org.br/seer/index.php/ecompos/article/view/28/29> Acesso em 15 mai. 2015.

RECUERO, Raquel. Diga-me com quem falas e dir-te-ei quem és: a conversação mediada pelo computador e as redes sociais na internet. Revista FAMECOS, Porto Alegre, no 38, abril, 2009. p.118-128.

RESNICK, Paul; VARIAN, Hal R. Recommender Systems. Communications of the ACM, New York, v.40, n.3, mar., 1997, p.55-58.

RICCI, Francesco; ROKACH, Lior; SHAPIRA, Brach; KANTOR, Paul B. Recommender Systems Handbook. Springer Science+Business Media, LLC, 2011.

RUIZ, Eva Espinar; RÍO, María José González. Jóvenes en las Redes Sociales Virtuales. Un análisis exploratorio de las diferencias de género. Feminismo/s 14, diciembre 2009, pp. 87-106.

SIBILIA, Paula. Os Diários Íntimos na Internet e a Crise da Interioridade Psicológica. Disponível em <http://antroposmoderno.com/antro-version-imprimir.php?id_articulo=1143> Acesso em: 15 mai. 2015. 
SILVA NETO, Orlando Celso da. Comentários ao Código de Defesa do Consumidor. Rio de Janeiro: Forense, 2013.

TAMBARA, Isabelle Milla; BATISTA, Osvaldo Henrique Santos; FREITAS, Cinthia Obladen de Almendra. A Proteção do Consumidor e as Técnicas de Neuromarketing no Comércio Eletrônico que Potencializam sua Vulnerabilidade. Revista Direito Empresarial - RDEmp, Belo Horizonte, ano 11, no.3, set./dez. 2014, p.89-107.

TAN, Pang-ning; STEINBACH, Michael; KUMAR, Vipin. Introdução ao datamining: mineração de dados. Rio de Janeiro, RJ: Editora Ciência Moderna, 2009. 900p.

TRUZZI, Gisele. Redes Sociais e Segurança de Informação. Disponível em <http://www. cnasi.com.br/redes-sociais-e-seguranca-da-informacao/> Acesso em 15 mai. 2015. 